\title{
LA «TUMBA»:RITOS Y REPRESENTACION COSMOLOGICA AYMARA
}

\author{
"¿Dónde están los muerios? Entre nosotros. A pesar de la muerte y \\ la putrefacción, estamos juntos».
}

Edmundo Motta Zamalloa

Schopenhauer.

«El hombre concibe el mundo de los muertos muy parecido al medio ambiente en el cua l cumple su ciclo vital, aunque más agradable y feliz pues en él ya no hay dolor, temor, enfermedad ni muerte. Si no llega a ese mundo podría entonces «llevarse» a algún ser querido que le haga compañia «.

\section{Robert Tocquet.}

\section{RESUMEN}

Como parte de una concepción escatológica, las poblaciones de origen aymara han desarrollado expresiones rituales e iconográficas que se han mantenido, con algunas variantes, en el tiempo y que posibilitan aproximar, en un espacio simbólico, a los vivos con los seres que han dejado de existir para este mundo. La "tumba» es ese espacio de encuentro, cuyas características configuran una representación cosmológica, pero también dan cuenta de ritos que corresponden a una antigua práctica en el modo de tratar a los muertos, con el propósito de salvaguardar la integridad de la familia y de la comunidad.

\section{INTRODUCCION}

Dejemos que LuisE. Valcárcel reseñeal cronista indio Guamán Poma: “En el mes de noviembre o Aya marcay quilla las ceremonias son dedicadas a los difuntos, cuyos cuerpos son extraídos de sus bóvedas que llaman pucuyo. Les dan de comer y beber y les renuevan sus ricos vestidos, poniéndoles plumas en la cabeza, y cantan y danzan con ellos, y los ponen sobre sus andas y caminan con ellos de casa en casa y por las calles del pueblo y después los vuelven a sus tumbas en las que colocan comidas, tejidos, vajilla de oro y plata al poderoso y de barro al sol y los entierran

\section{Antropólogo}

nuevamente»(Vaicarcel,1984,vl.3:345).

Tales ceremonias incluian la necesaria exhumación de cadáveres para entrar con ellos en contacto directo y renovar los recipientes funerarios con cosas de comer y beber. Una misma ideabásica sostenia esta práctica: los muertos continuaban integrados al cuerpo social, existiendo, de algún modo, en otra dimensión. Las modificaciones introducidas por la historia colonial, en particular por las catéquesis, se relacionan más con el aspecto expresivo que con la ideología misma acerca de la muerte.

Como manda la tradición en muchas partes del mundo, en Tarata y localidades aledañas (1), el primero de noviembre está dedicado a los difuntos. En el calendario andino esta fecha no sólo señala la segunda 
parte del año, sino una serie de rituales que entremezclan en sus mensajes los destinados a rememorar a los muertos y a propiciar que el próximo verano sea más húmedo(2), en un sentido en que el compromiso con los muertos parece ser, ante todo, el camino que refuerza la vida del hombre, conservándola y protegiéndola. Como, en efecto, ocurre entre los tarateños, para quienes los meses de estío han cedido a las primeras lluvias que llegan al pueblo, junto con el recogimiento de los que vuelven vestidos de luto y traen consigo especies de ofrendas para sus muertos.Junto a la variada naturaleza de las ofrendas, los dolientes aymaras han levantado una especie de altar, denominada precisamente "tumba", cuya función es la de posibilitar el acceso del alma del ser querido al más acá, el «acapacha».

Pasada la sorpresa que produce la primera impresión se puede comprobar que el término "tumba» no designa una sepultura,como suena usualmente al oído, sino todo lo contrario; pues en realidad se trata de una representación a la manera de un altar.que es parte, o mejor aún, es el centro obligado de un ritual que incluye visitas y responsos de dolientes, deudos y amigos. Contrariamente a lo que se podría pensar, no se trata de la tumba del cuerpo,sino de la tumba del alma.

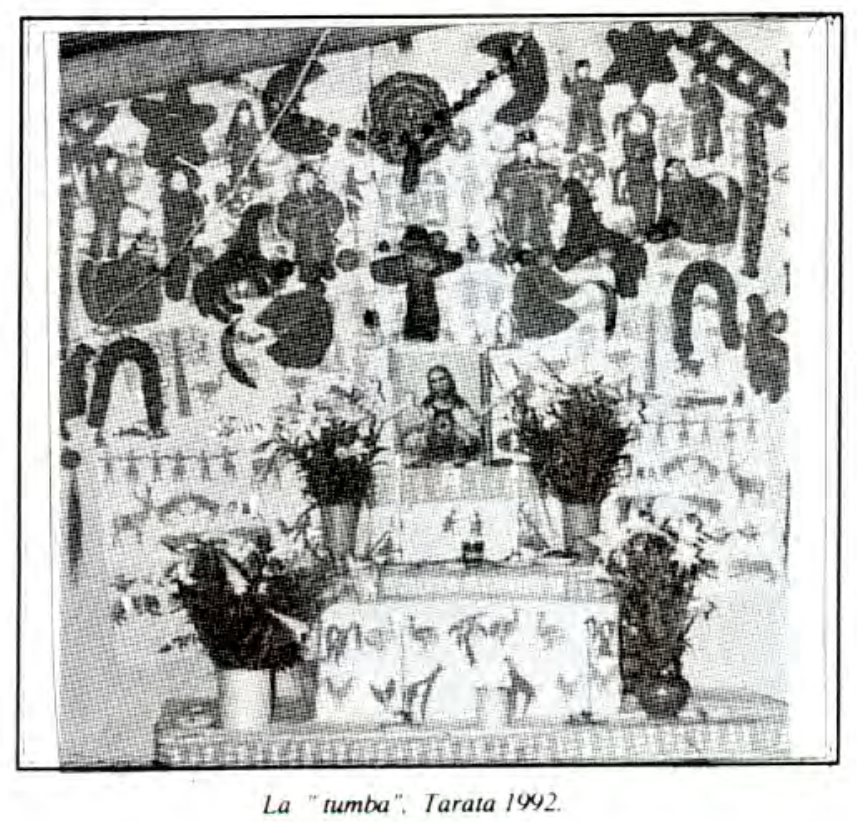

En el trabajo que sigue daremos cuenta de esta manera de conmemorar a los muertos, en la que la confección de altares tiene particular importancia en el altiplano aymara, por la capacidad que posee para traducir una ideología escatológica, la cual no hace, sino enriquecer y complementar una extensa concepción acerca de la vida y del mundo.
"TUMPA» $Y$ «TUMATHA».-

El término "tumba» designa convencionalmente el lugar donde se da sepultura a un cadáver. Su acepción en español transmite el mismo significado que el término latino "tumba" y el griego "tymbus".

En aymara existe el vocablo "tuma", y su derivado "tumatha", que significa "andar alrededor de la plaza o de otras cosas", también "andar de pueblo en pueblo, o de casa en casa, o de calle en calle". Ludovico Bertonio en su conocido diccionario de la lengua aymara (1612) menciona "tumaquipatha", que quiere decir "rodear o cercar muchos a uno".Asociado a los vocablos "hacha" $y$ "hachatha» significa «ir de casa en casa llorando cuando se muere alguno, especialmente a casa de sus parientes y amigos a donde solía acudir el difunto".

En el diccionario preparado por Domingo Llanque (3) podemos reparar en el término raíz "tumpa" que significa "visitar, echar de menos"; y sus derivados "tumpanina" y "tumpasinina" que refieren sucesivamente al acto de «ir a visitar/ir a echar la culpa" e «ir a visitar a un familiar para saber cómo está".

Conociendo las variaciones fonéticas de las lenguas quechua y aymara al castellanizarse, en especial los cambios y confusiones de la «i» por la «e», de la «u» porla "0», de la «p» por la «b", podemos inferir que los términos aymaras "tuma" y "tumpa" se convirtieron en "tumba", pero conservando su significado original, ampliamente demostrable, con las representaciones cosmológicas y, en particular, con las experiencias rituales recientes.

La referencia a este tipo de prácticas ritualizadas es de especial importancia para entender el objeto quenos ocupa. De primera intención, debemos mencionar que el «ir de casa en casa llorando cuando se muere alguno" no significa en la actualidad, probablemente como en los tiempos de Ludovico Bertonio, que este recorrido se lleve a cabo cuando la persona acaba de fallecer y su cadáver todavía se encuentra insepulto, a menos que el grupo doméstico del difunto o la unidad étnica a la que pertenecía, pudieran reproducir lo que el alma de la persona suele hacer en el imaginario andino: recorrer durante su agonía y días después de fallecido, los lugares que frecuentaba en vida. En cambio, cobra plena validez el hecho de que tales recorridos se hacian a casas de los difuntos ya inhumados, en recuerdo de su memoria. Desde este punto de vista, son demostrativos los recorridos que protagonizan los "animeros" de Antabamba(4), personajes designados 
para responsabilizarse de las celebraciones de Todos los Santos. Estos personajes visten de luto completo, incluyendo chullo y poncho igualmente negros,que les otorgan un aspecto tétrico; y visitan las casas de los difuntos del año para consolar a los deudos; entonan canciones en voz de falsete y se guían en la noche con velas encendidas (5).

En Tarata y poblaciones adyacentes, las visitas de Todos los Santos revisten el mismo significado que entre los animeros; pero además implica que la tumba tiene un valor particular:allí se encuentra el alma del difunto.De tal modo que estas visitasabrigan un doble sentido al alma, y, consiguientemente, a los dolientes deudos.

\section{ALGO MAS QUE SUEÑO PROFUNDO}

Admitida como cosa de la fatalidad, sin embargo la muerte comienza a pulsar las fibras existenciales, desde que se anuncia en las experiencias y visiones premonitorias hasta el momento en que asume su forma concreta en el cadáver. Una vez que el muerto se ha instalado en la casa, ata en torno de su inevitable presen cia a la familia y a los miembros de la comunidad con quienes ha sostenido vínculos religiosos, festivos, laborales o simplemente, porque siendo pocos en el pueblo, «todos se conocen».

Algo que conmociona a los asistentes se revela desde el cadáver y permanece junto a él, agregando a la circunstancia una mayor dosis de sacralidad y temor: el alma, acabada de ser liberada por el hecho de morir y que se mantiene en el centro de esa circunstancia antes de iniciar su vagabundeo por la quebrada de Chacavira y las inmediaciones de la comunidad.El velorio es precisamente esa circunstancia en la que están juntos el muerto, el alma y los dolientes. En consecuencia, todos los gestos rituales, de aqui en adelante, estarán orientados a proteger a los dolientes y a separarlos del muerto y, por otra parte, a evitarle sufrimiento al espíritu en su viaje y aislamiento definitivo.

Hay un momento culminante durante el velorio, cuando sobreviene la medianoche. Los deudos deben rodear al féretro, y uno porvez, abrazarlo pidiendo perdón al difunto por las faltas. Si es padre dirán:"papacito, perdóname si te he ofendido"; pues el difunto no podrá alcanzar el descanso, si todavía existe pendiente algún agravio contra él, por pequeño que fuere. Para estar seguros de haber conseguido la armonía que permitirá la paz del muerto, los deudos se autoimponen otros actos de penitencia, como andar de rodillas alrededor del féretro, aunque es conocido que tales sacrificios corporales son poca cosa, comparados con el dolor del corazón que muchas veces arrastra al desvanecimiento.

Como la noción de la muerte está asociada al sueño, en el sentido de que no es más que un sueño pero más profundo, los acompañantes procuran conjurar el sueño, recurriendo a algún género de juego: a las adivinanzas o a las cartas; aunque guardan alguna preferencia por los juegos con maíz, denominados «nonespares", que consiste en tomar en la mano,al azar, unos granos de maíz al tiempo que reta al vecino «nones o pares"; si este acierta recibe en pago maíz, si nolo hace entrega el suyo; hasta que el "puñado" va cambiando de un jugador a otro, a medida que transcurre la noche.

El término "kacharpaya", aplicado para todaforma de despedida, es empleado también para despacharal muerto, en especial cuando se trata de niños. De pasal camposanto, el muerto recibe una misa cristiana de cuerpo presente en la iglesia del pueblo. La muerte de un niño es motivo de otra interpretación,como ocurre en la localidad vecina de Cairani. Elniño es en realidad un ángel, y su muerte se produce en estado de gracia por lo que subirá directamente al cielo. En su sepelio, las mujeres entonan canciones con acompañamiento de charango:"Ya retornas ángel mío/ a la mansión de los cielos/ dichoso tú que te vas/ sin saber lo que es dolor// Si te pregunta San Pedro/ quienes han sido tus padres/ dirás: San José y la Virgen María/ y voy al servicio de Dios"(6).

El ataúd del niño es de color blanco (signo de pureza), a su cadáver han agregado alas de papel (el espíritu del niño es un ángel), lleva atado a la cintura una cinta celeste (que enlazará al espíritu de los padres y padrinos de la criatura, para que cuando mueran sean conducidos a la "gloria"), y a los costados del pequeño cuerpo han colocado un balde y una escoba (medios de los que se servirá la criatura para explicar los pecados a Dios). Al retorno del cementerio la madre debe cargar en la espalda una piedra en medio de acompañantes que cantan y bailan (la piedra que carga la madre es una especie de castigo por la muerte del niño).

El "día siguiente" se produce a los ocho días del fallecimiento, durante el cual se deberá disolver el contacto que el difunto mantuvo con sus ropas, mediante el agua y el fuego en el río. Se lavan las ropas que pueden ser reutilizadas y queman las que están muy gastadas. Mientras el fuego consume las ropas del difunto, los celebrantes observan con sumo cuidado y desde una prudente distancia, las llamas de fuego y el humo, esperando con ansiedad percibir el perfil del rostro de la persona que fallecerá próximamente. Permanecen 
descalzos y con los pies sumergidos en la corriente de agua. Las mujeres cogerán ramas de aliso o molle para castigar a los deudos, al tiempo que dicen, culpándolos: "por qué (te) (lo) has comido a tu papá» (mamá, hermano, hijo...).

En el mismo escenario han dispuesto una mesa ritual, conteniendo especies de coca y licor que servirán de ofrenda antes de emprender el retorno a casa, donde, luego de vestir al difunto con la ropa lavada en el río, continuarán el velorio. El cuerpo del finado ya reposa en el cementerio, pero "él» sigue entre ellos. El curso del día siguiente comprende,pues, tres escenarios: la iglesia, el río y la casa. Los ritos son sucesivamente: misa católica, lavado y quemado de ropa, y velación del difunto.

El "cabo de medio año", a los seis meses, permite a los deudos mudar medio luto; y cumplidos los doce meses sobrevienen los ritos de "cabo de año", en el que los deudos pueden mudar el luto completo. Los ritos se desarrollan entre el templo del pueblo y la visita al cementerio donde algún miembro de la familia,o cercano a ella,pronunciará un discurso elogioso recordando la memoria del difunto (7).Continúa en casa de los deudos, donde se hainstalado una mesa ritual en el piso, sobre un aguayo de colores: tarea de la que se encargan de modo particular los parientes espirituales. Los asistentes contribuyen voluntariamente con especies, con el propósito deayudar en los gastosyporque es la expresión concreta de la solidaridad. Sobre el aguayo se forman grupos decoca, de los que cada asistentedebesacar tres hojas (Padre, Hijo, Espritu Santo) que deposita en un recipiente, añadiendo algo de azúcar. Enseguida, se colocan de rodillas para darse el perdon reciprocamente. Todo este acto se conoce con el nombre de "misacha». Después se hacen los cambios de botella, bebiendo del propio pico. Pasada la hora del almuerzo (o lo que fuere) se lleva a cabo la ceremonia del cambio de luto.

Esta ceremonia marca el momento final de la atadura al difunto; al mudar de luto sentirán una suerte de liberación. La ceremonia mezcla la picardía con la gracia, pues los deudos han preparado sus trajes de colores, o los que han comprado especialmente para empezar la nueva etapa de vida. Para dar énfasis al acto, algunos recurren inclusive al disfraz. Si entre los deudos hay un cónyuge sobreviviente, el rito de cabo de año reviste una significación especial. Mientras quelos demás deudos-hijos,hermanos,padres-terminan sólopormudar el luto, el viudo o viuda debe "casarse» en medio de un ambiente de jocosidad en la que alguien ,disfrazado de cura, debe casarlo con un o una joven. Por eso, quizás hay quienes prefieren llamar a este rito como «fiesta de cabo de año". Pues así como se ha cambiado el negro por la ropa de colores, se ha cambiado la tristeza por la alegría, la muerte por la vida, y el viudo o viuda pueden rehacer su sexualidad.

Si bien, es cierto que con el "cabo de año" concluye, cuando menos ritualmente, la separación de los deudos con respecto al muerto, resaltando el significado de protección a los sobrevivientes, otro rito especial se encargará de convocar el alma del difunto y preparar su aislamiento definitivo.

Las celebraciones de la "tumba" pueden introducirse en cualquier momento de este ciclo que va del velorio al cabo de año. Sin embargo, es necesario tener en cuenta el tiempo transcurrido desde el fallecimiento. Aunque el ideal es que coincidan la "tumba" con el "cabo de año", ocurre con relativa frecuencia queel decesose produceamuy cortadistancia del primero de noviembre, pudiendo, en este caso, tener hasta dos "tumbas". Debido a este problema con el tiempo, en poblaciones algo más distantes de Tarata, aunque dentro de los mismos aymarahablantes, como en Candarave, se levantan las tumbas hasta por tres años consecutivos, y en otras, dos veces. Si en el cabo de año los deudos se separan del muerto, en la ceremonia de la «tumba" el alma del difunto debe separarse del mundo.

\section{EL MUNDO QUE VEMOS}

Dos aspectos son cuidadosamente observados a la hora de decidir el armado de la tumba: el lugar de la casa y las personas que participarán en él. Forasteros o gente extraña a la relación de parentesco sanguíneo, son excluídos de participar en un acto que es reputado sólo para el círculo familiar y que debe cumplirse a puerta cerrada. En cuanto al lugar, la tumba se dispondrá en la parte más adecuada de la casa, mucho mejor si es el mismo lugar donde expiró la persona, pero también conciliando esta idea con la comodidad que se deberá ofrecer a los celebrantes.

Una tela de dos metros por lado aproximadamente, es extendida sobrela pared. Su color puede variar de acuerdo a la edad, sexo y condición civil del fallecido. Blanco, si fue niño o niña. Celeste, si fue un hombre joven o adulto, pero soltero. Rosado, si fue mujer joven o adulta, pero soltera. El negro es reservado para los adultos de ambos sexos, casados (Ver gráfico). 


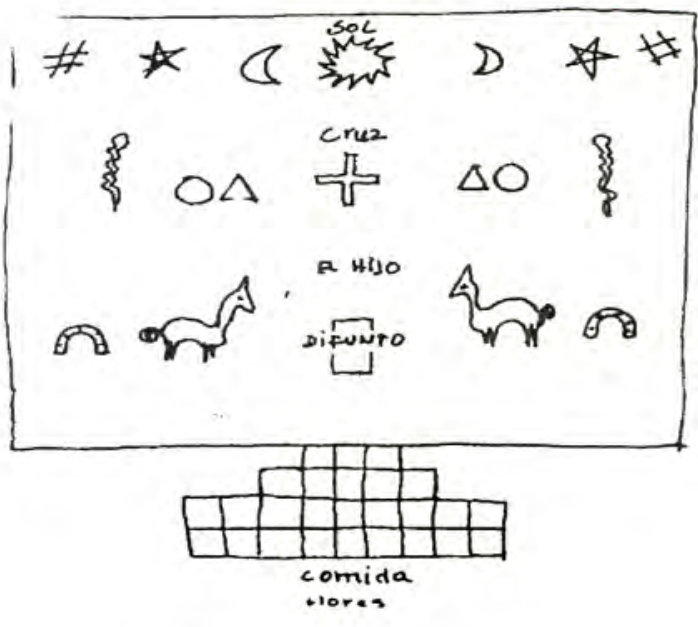

Presentisción esquemática de la "tumba"

Las figuras o íconos que penden sobre la tela son hasta de tres clases. En papel blanco, las figuras que corresponden a la flora, fauna, a los elementos cristianos; otras tantas perfilan objetos de la modernidad, o a los elementos de la cosmología (sol, luna, estrellas) o recogen los seres míticos del imaginario religioso católico-andino.

Otro tipo de figuras infaltables están hechas a base de harina de maíz o trigo. Se distinguen los panes en forma de sol, luna, estrellas, serpientes, llamas, escaleras que ayudarán a las almas a escalar alturas; aves del entorno y herrajes que recuerdan a la arriería, y que posteriormente se han convertido en amuletos de la buena suerte.

Además se han considerado productos comestibles que se pueden recoger en las quebradas cálidas, como el buen abridor,tunas o manzanas; otros que afloran en las chacras del medio o provienen tras los pasos de los migrantes. Cerrando el cuadro, penden coronas de flores confeccionadas en papel crepé.

Aunque den la aparente impresión de un caos, estas figuras no están dispuestas de cualquier manera sobre la tela.

Siguiendo una línea imaginaria vertical, trazada por el centro, están colocados los símbolos cristianos templo y cruz, un cuadro del corazón de Jesús, y la fotografía del fallecido-, que son los únicos que no están repetidos. En cambio, a ambos lados del eje central, están dispuestos los demás elementos de tal modo que: los delaizquierdase repiten en los de la derecha, exactamente como la imagen del espejo duplica al objeto que refleja. Así, hay dos soles, dos lunas, dos escaleras, etcétera.
Algunas veces, el sol alcanza el estatuto de elemento cristiano al ser colocado en el centro y, evitar así, que se repita.

A continuación de este recuadro está dispuesta, en la parte baja, una mesa de forma escalonada, de tres niveles, en la que se han colocado: velas que permanecerán encendidas las veinticuatro horas del día, recipientes con flores, platos con los potajes que gustaba al fallecido en vida.

Los rebozos de mantel de contrapaso de los tres niveles, están decorados con figuras de penitentes, hechas en el mismo tipo de papel que el resto de figuras de la pared. Los penitentes forman una larga cadena de hombres y mujeres,enlazados por las manos, que aparentan estar disfrazados y ejecutando una danza(8).

Al pie de la mesa, o la tumba, cajas de cartón contienen panecillos de maízo pasteles en miniatura, que la gente llama indistintamente "maicillos»,los que serán distribuidos, en acción de gracias, por los dolientes.

El contexto de la tumba está enmarcado por la habitación acondicionada para el caso: bancas, sillas, mesa, dispuestos al frente o a un costado del altar, observando la idea de que los celebrantes permanezcan, mientras acompañan, dando la frente a la tumba. Si bien, no están obligados a nada en especial, pueden conversar, orar, fumar cigarrillos, beber licor.

\section{DE ARMAR Y BAJAR LA TUMBA}

El armado de la tumba es un rito con el que están familiarizados todos en el pueblo a fuerza de reiterarse en el tiempo, pues nunca falta un muerto del año o algún ser querido a quien recordar y esperar con ofrendas. $A$ veces se menciona a un personaje especializado en recortar figuras de papel, pero más por su destreza que por un dominio particular en elaborar símbolos. Nadie dirige el ritual, pues el procedimiento es harto conocido, así como las valoraciones generales.

Un factor muy importante para el armado es, naturalmente, el tiempo. La tumba tiene que haberse culminado de armar antes de las doce en punto del primero de noviembre. Cuando se anuncia el sol en el centro del firmamento, los dolientes se colocan frente a la tumba, de pie o de rodillas si lo prefieren,entonan oraciones en coro, llorano expresan sualegría, porque en ese preciso instante el alma del difunto hace su ingreso a la tumba, a la casa y,al otro lado de la puerta, las otras almas retornan al pueblo donde nacieron, vivieron y murieron.Aunque el difunto hubiera partido al más allá en 
otro lugar, por distante que estuviera, tornará al pueblo donde nació y vivió.

Los dolientes pueden a veces percibir que ha llegado el alma de su difunto, pues las velas encendidas muestran sus llamas vivas y rectas, y alrededor se respira un aire en completa paz y silencio. Si acaso vuela alrededor una mosca o se oye en la proximidad el graznido de unave, tanto mejor, pues es señal inequívoca de que el alma ha llegado. No pocas veces esparcen cenizas en la puerta de la casa, aquélla por donde se piensa que puede hacer su ingreso, para ver, pasadas las doce del día, una huella de zapato o el rastro de un pie descalzo.

Más tarde acudirán los visitantes. No son muchas las personas fallecidas en el año y ya se sabe en que casas se han levantado las tumbas con los que mediará la obligación moral de hacerle una visita. El acto de responso principal se ha realizado al mediodía, y si fue con la presencia de un responsador de oficio o el sacerdote de la parroquia, tanto mejor, pero a partir de ese momento la puerta de la casa permanecerá abierta durante la noche hasta que medie las doce del día siguiente, no tanto por facilitar el horario de los acudientes, como porque el mandato de la fe es que la tumba permanezca abierta las veinticuatro horas.

\section{El primer acto del visitante consiste en saludar} al alma, dedicándole una oración. Rezará padrenuestrosi el difunto es varón; avemaría si es mujer. Con una rama de ruda o clavel asperjará "agua de iglesia" sobre el retrato del difunto, el cuadro de Jesús y demás objetos simbólicos de la tumba.Terminado el acto dirá: «que se reciba esta oración", y aguardará en uno de los asientos libres los maicillos que un deudo, representante del alma, le dará en pago a la oración recibida. "Es el alma la que le paga» y, en consecuencia, "está obligado a recibir». En caso de negarse deberá abandonar la casa, pues los seres mortales no deben oponerse a la voluntad de las almas.Casi no ocurren casos de expulsión forzosa, porque hay pleno conocimiento de la tradición, aunque no faltan anécdotas que ilustrarán lo contrario, pero más con el propósito de evitar un escarmiento. Ciertamente, la excepción será tolerada cuando se trata de visitantes forasteros.

El escenario toma las características propias de un velorio a la que ayudan las expresiones de pesar y los juegos con maíz. La idea de velorio, que es una expresión del acompañamiento, viene porque el difunto está en la casa no como cadáver sino como alma y reclama la compañía de los deudos, amigos y conocidos. Nadie está obligado a pasar las veinticuatro horas, pero tampoco se trata de una visita fugaz; después de un tiempo prudencial y previa una justificación que no se dice, pero que se entiende, se puede retirar, pues hay otras almas en el pueblo que convocan al mismo deber.

En el campo, en la plaza, en las inmediaciones del cementerio, algunos adolescentes hacen volar cometas "para ayudar a bajar a las almas".

Al aproximarse las doce del día siguiente, los dolientes y amigos se disponen para desarmar la tumba. El alma no puede permanecer por más tiempo. Los presentes entonan oraciones, o cánticos que suelen ser más sentidos, se toman fotos, si hay fotógrafo, antes de iniciar el desarmado. El retrato del difunto, el cuadro de Jesús, la Cruz, los platos con comestibles son "bajados" con la veneración que reclaman los objetos sagrados. El turno de los panes sigue un orden establecido, de acuerdo con la jerarquía del símbolo que representa y la proximidad del parentesco o la amistad. El sol,que es el símbolo más importante, será entregado al sobreviviente más cercano del difunto.Y asi continuará el reparto de los panes en la idea de que será asimilado a su cuerpo,en acto de comunión. La entrega de los panes es interpretada, en cierta forma, como la herencia que el alma deja a los sobrevivientes.

A su vez las figuras de papel son recogidos y doblados, reservados para otra tumba, las que se otorgarán como préstamo, o serán incinerados, si se desea que allí debe concluir todo.

La bajada de la tumba no puede terminar, si no se ha invertido la mesa para que el alma no tenga ningún obstáculo al salir de la casa en su largo viaje al "alajpacha", ni su alejamiento sea seguido por algun miembro de la familia. Entonces se abren puertas y ventanas para que ingrese por ellas el aire y la luz, y los presentes se disponen a almorzar. Con dicho acto concluye la ceremonia; después, deudos y amigos acudirán al cementerio, llevando flores a la sepultura del difunto.

\section{UN COSMOS DENTRO DE OTRO}

¿Por qué en Tarata, y en general, los campesinos de origen aymara deben armar una tumba para esperar el alma del difunto? En otras comunidades y pueblos rurales, y aun urbanos, bastaría poner el retrato del difunto en una mesa con flores, tal vez una vela encendida y comestibles de los que gustaba en vida. En cambio, en Tarata, además, deben levantar una tumba, pues de otra manera "el alma de su ser querido, al no encontrar la tumba, se regresará triste al más allá", o 
como medijera J.Condori,el mayor mandamisa de Ticaco: "no sería posible que entrara en la casa».

En lugar de asociarse con la sepultura, la tumba se acerca más bien a la noción de casa, que significa, en el otro extremo, el lugar de origen, del nacimiento, de la vida, en vez del de la finitud y de la muerte.

La casa es también una especie de cosmos, si se prefiere, en pequeño (9), al punto que al construirla se tiene presente la idea de que se está refundando el cosmos y existen obligaciones rituales contraídas e inevitables como pagar la tierra con la sangre sacrificial de una llama o cordero (10).La idea de refundación del cosmos supone la inclusión de sus elementos constituyentes, de manera particular, en lo que se refiere a la conformación de la estructura de la casa y de su orientación en el espacio. En ese pequeño cosmos se desenvolverála vida, desde el nacimiento hasta la muerte. La casa es, pues, el referente primero y más importante de la existencia del individuo y de la sociedad. Su negación es la sepultura que,en aymara, se denomina "aya utu", tanto como la muerte lo es de la vida.

Es en la casa donde el ideario aymara localiza la tumba, el altar que posibilitará el encuentro final entre el alma del difunto y sus deudos, entre los seres del más allá con los vivientes de este mundo. Y ese encuentro requiere de un medio, una mediación: la tumba. A su vez se trata de un espacio que reúne características propias que lo aproximan a la de un nacimiento navideño. En los términos que explicara J. Condori, la tumba, sin lugar a dudas, era un nacimiento, pues así como el ser humano al momento de nacer encuentra un mundo integrado con su cielo, sus estrellas; en la tierra: agua, árboles, animaless y demás seres y objetos que configuran la existencia, el alma del difunto deberá encontrar en la tumba un cosmos semejante. De allí que en la tela, que representa el cielo, estarán contenidos el sol, la luna, las estrellas, escaleras, animales de la fauna local y plantas, a más de otros seres y objetos generados por la historia, que en conjunto, constituyen el cosmos, donde accederá el alma, el único lugar en que permaneserá durante veinticuatro horas, finalizado el cual abandonará este mundo, en su salida definitiva al "alajpacha". Establecido de este modo, la tumba no sólo posibilitará el acceso del alma,sino que evitará su postrer afliccićn y vagabundeo, y el consiguente riesgo que conlleva para la convivencia de la comunidad.

Dentro de la casa, la tumba es, a su vez, otro cosmos más reducido, cuyo armado responde igualmente a la idea de refundación, sólo que, en este caso, su posesor y habitante es incorporeo. Hallamos,en consecuencia, tres espacios cósmicos que se suceden uno al interior del otro. El primero, el más pequeño es la "tumba", contenido en otro mayor definido por la "casa", y éste integrando al "cosmos" que envuelve a la comunidad (Ver grafico).

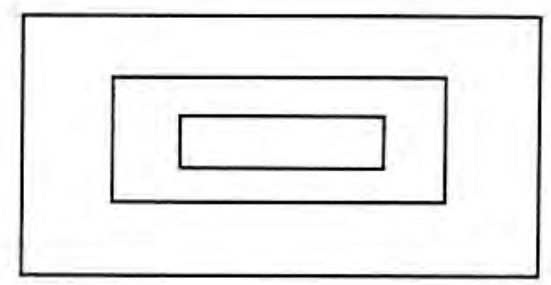

Por otra parte, la tumba responde muy bien a la idea de retablo, como la representación de escenas de la vida diaria, del trabajo, de los ritos y festividades de la comunidad y hasta de las formas de concebir el mundo. Retablo, casa o tumba vienen a ser nociones equivalentes, expresiones de una matríz ideológica compartida por quechuas y aymaras (11).

\section{A PROPOSITO DEL DIBUJO DE SANTA CRUZ PACHACUTI}

El famoso dibujo cosmológico del cronista indio Juan Santa Cruz Pachacuti Yamqui Salcamaygua (12) ha soportado distintas lecturas, quizás no siempre conformes a las ideas que el cronista quiso expresar o representar. Como escribe textualmente al inicio de su crónica la idea fundamental de su "Relación..." como del dibujo en sí estaba orientada dentro de las intenciones de evangelización de la iglesia. No buscaba Pachacuti Yamqui expresar cómo pensaban los indios acerca del mundo, sino de resaltar la plancha que representaba al dios Wiracocha Yachachi, dios invisible y creador del mundo y de todas las cosas, como el sol, la luna y demás cosas que estaban subordinados al dios invisible.Escribe el cronista que para resaltar esa "plancha" dibujaba alrededor las demás cosas visibles del mundo. La idea refleja perfectamente la intención del cronista y el espíritu de la época, como ha analizado, por ejemplo, Duviols (13).

Sin embargo, cuando menos para las pretensiones de este trabajo, no interesa tanto la concepción del mundo de los indios vencidos, sino el dibujo de Pachacuti Yamqui, en la medida que expresa la representación del mundo que él mismo, indio aculturado, defensor de la nueva religión en plena campaña de extirpación de idolatrías, tuvo de las cosas y del universo. "Asi está dibujado en la casa del Coricancha": en el 
centro se encuentra el creador, ocupando la parte superior del cuadro, arriba del cual hay cuatro estrellas formando una cruz. Una línea imaginaria vertical que la divide por el centro define los lados derecho e izquierdo. En el derecho están los elementos masculinos,incluido el hombre; en el otro, los femeninos, incluido la mujer.Debajo del cuadro aparece una "collca-pata", que algunos intérpretes han llamado simplemente granero, almacén o terraza. El perfil del dibujo que semeja el frontis de un templo, configura al conjunto dentro de la concepción cristiana, pues se trata de su símbolo arquitectónico.

Por su parte, la tumba contiene representaciones de los diferentes elementos del entorno cósmico, como aquellos objetos correspondientes alamodernidad. En el centro están ubicados los elementos cristianos y el retrato del difunto.El cuadro concluye en la parte inferior con una mesa de tres niveles en la que están depositadas las ofrendas, donde predominan los comestibles. Complementan ala mesa, los depósitos que contienen maicillos destinados para la comunión. Pocas veces, esta representacióntiene variantes, y cuando esto ocurre, por lo general, no altera la estructura de la tumba y mucho menos, su significado.La tumba se abre a partir del eje central-cristiano y continúa sobre un plano propiamente cosmológico. La dualidad, un principio básico de su estructura, duplica en el campo derecho, exactamente como un espejo, lo que está en el izquierdo.

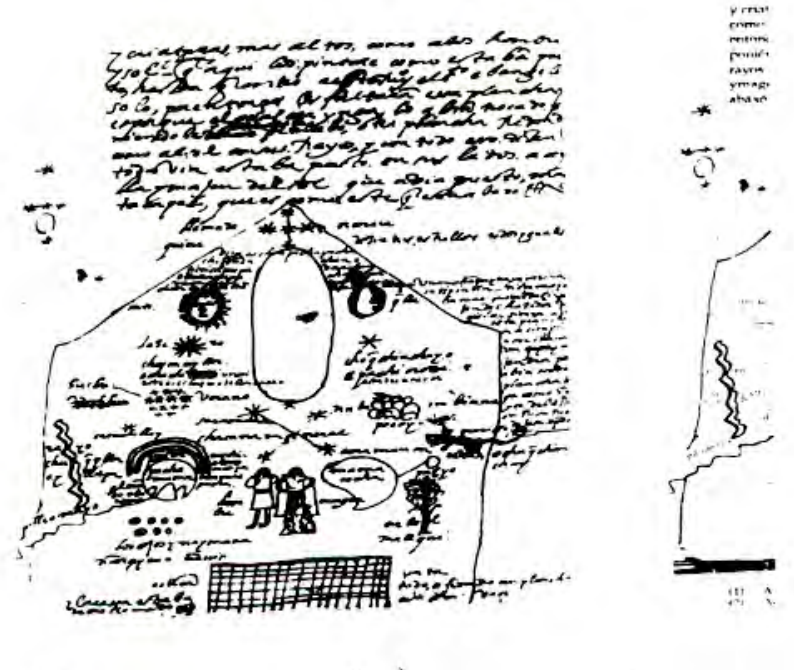

-Mapa cosmológico d e. Paçhacuti. Yamqui

Podrían encontrarse muchas similitudes entre la tumba y el dibujo de Pachacuti Yamqui, quien fue, al fin y al cabo, un cronista cuyo grupo étrico estuvo ubica- do en la frontera linguística entre quechuas y aymaras del altiplano puneño, y que, probablemente, conoció en su significado original la "tumpa" o Tumatha" que registró en su diccionario Ludovico Bertonio. De lo que no cabe duda es que la tumba es una representación cosmológica con base ideológica cristiana, tanto como lo es el dibujo de Pachacuti.No podía ser de otra manera entre los campesinos de hoy, después de cinco siglos de contacto con la religión de Occidente.Ocurre con la ideología, lo que con el lenguaje, se comunican en aymara o quechua y castellano, a veces, indistintamente, expresando en castellano lo que sienten en aymara; y no siempre la palabra expresa a cabalidad el pensamiento.

\section{NOTAS}

(1) En otros trabajos me he ocupado de esta provincia andina de Tacna. Por ejemplo, ver: "Racionalidad Campesina y control social del agua:cuenca alta de Sama»;en Nueva Imagen Nro.5, 1994.

(2) Ver: "Los muertos y los diablos entre los Laymi de Bolivia», de O.Harris; en Chungara, Nro.11,AricaChile,I983.

(3) Domingo Llanque Chana y otros, en: Diccionario Aymara-Castellano, Lima-Puno,1984.

(4) Experiencia personal en la provincia de AntabambaApurimac, noviembre de 1985.

(5) No deja de ser interesante la hipótesis de encontrar en el baile de los animeros el origen del "Alcatraz", a pesar de la distancia geográfica y de grupos étnicos distintos que las expresan (anotación'extraída de un programa de tv, 1993).

(6) Entre las monografías escritas portesistas de laENSF "I de $\mathrm{M}$ »,se recomienda consultar la monografía sobre el distrito de Cairani, de Salgado E, Margarita,Tacna-Perú, 1968.

(7) El cronista Huamán Poma refiere esta costumbre de dedicarles a los muertos discursos elogiosos como actos obligatorios(L.Valcarcel,v.3,1984).

(8) Hay escenas pintadas de penitentes en los petroglifos de Mikulla con las mismas características de las tumbas de Tarata. Ver: Mikulla, el Valle de las Piedras Grabadas, de J.Gordillo y otros,1992.

(9) Consúltese el estudio etnohistórico de P.Duviols sobre Pachacuti Yamqui,en la edición de 1993, y a M. 
Eliade sobre el tema de la sacralización del espacio y cosmogonía en: Lo sagrado y lo profano, 1973.

(10) Numerosos trabajos etnográficos sobre ritos agroganaderos dan cuenta acerca del empleo de la sangre sacrificial en la propiciación de la fertilidad. Véase para este propósito la Exposición de Nachtigall, en

\section{REFERENCIAS BIBLIOGRAFICAS.-}

\section{Aranibar, Carlos}

1957 Notas sobre la necropompa entre los incas. Rev.Mus.Nac.de Cultura,Lima Perú.

Bertonio,Ludovico

1612 (1956) Vocabulario de la lengua Aymara.La Paz-Bolivia.

Cereceda,Verónica

1985 Aproximaciones a una estética andina.Ts. PUC,LimaPerú.

Eliade, Mircea

1973 Lo sagrado y lo profano.Guadarrama, Madrid-España.

Gordillo, Jesús y otros

2 Mikulla,el Valle de las Piedras Grabadas. Tacna-Perú.

Harris, Olivia

1983 Los muertos y los diablos entre los Laymi de Bolivia. Rev. Chungara, Nro.11, Arica-Chile

Lanque Chana, Domingo y otros

1984 Diccionario Aymara-Castellano. Lima/Puno.
Allpanchis Nro.8, Cusco-Perú, 1975.

(11) Duviols, íbid.

(12) Véase la edición preparada por P.Duviols, 1993.

(13) Ibíd.
Nachtigall,Horts

1975 Ofrendas de llamas en la vida ceremonial delospastores.En:Allpanchis,Nro.8, Cusco-Perú

Pachacuti Yamqui Salcamaygua,Juan

1613 (1993) Relación de antiguedades deste reyno del Piru. Estudio preliminar de P. Duviols y C. Itier; Cusco-Perú.

Palacios Ríos, Félix

1983 Muerte en los andes:estructura social y ritual entre los pastores aymaras.

Urbano, Osvaldo

1974 La representación del tiempo y el espacio en la fiesta. Rev.Allpanchis,Nro.7.

Valcárcel, Luis

1984 Historia del Antiguo Perú a través de la firen te escrita.E d Juan M eja Baca,Lima,V.3.

Vincent-Thomas, Lewis

1982 Antropología de la muerte, F.C.E. México.

Salgado, E. Margarita

1968 Monografía del distrito de Cairani. Ts.ENSF, Tacna-Perú. 